\title{
Water content of faeces is higher in the afternoon than in the morning in morning-fed dogs fed diets containing texturised vegetable protein from soya
}

\author{
Richard C. Hill $^{1 *}$, Colin F. Burrows ${ }^{1}$, Gary W. Ellison ${ }^{1}$, Mark D. Finke ${ }^{2} \dagger$, Jennifer L. Huntington ${ }^{1} \ddagger$ \\ and John E. Bauer ${ }^{1} \Phi$ \\ ${ }^{1}$ Department of Small Animal Clinical Sciences, College of Veterinary Medicine, University of Florida, Box 100126, \\ Health Science Center, 2015 Southwest 16th Avenue, Gainesville, FL 32610-0126, USA \\ ${ }^{2}$ Alpo Pet Foods, Inc., Allentown, PA, USA \\ (Received 13 October 2010 - Revised 12 January 2011 - Accepted 28 January 2011)
}

\begin{abstract}
Faecal moisture content can determine whether faeces appear soft or firm, and faecal character can influence whether owners are satisfied with a dog food. In a previous study, dogs appeared to produce softer faeces after noon. The purpose of the present study was to determine whether time of defecation affected canine faecal water content. A total of eight hound dogs were fed one of four canned diets as a single meal each morning for 1 week per diet in a Latin square design. All four diets contained approximately $77 \%$ moisture and, on a DM basis, $24 \mathrm{MJ} / \mathrm{kg}$ gross energy, $23 \%$ crude protein, $32 \%$ crude fat, $31 \% \mathrm{~N}$-free extract and $1 \%$ crude fibre. The proportion of dietary protein from soya-derived texturised vegetable protein (TVP):beef was 0:100, 14:86, 29:71 and 57:43, respectively. Soya carbohydrate partially replaced maize starch as TVP increased. Faeces were collected by direct catch during the sixth morning and afternoon of each diet period. Mean faecal moisture content was greater in the afternoon than in the morning $(79 v .71 \% ; P=0 \cdot 01)$ and increased with dietary TVP $(P \leq 0 \cdot 0001)$, and there was an interaction between time of day and percentage TVP $(P=0 \cdot 003)$. Faecal moisture content differed from morning to afternoon only with TVP in the diet. Faecal wet weight was similar from morning to afternoon. This suggests that time of day and presence of TVP from soya should be taken into account when evaluating the effect of a diet on faecal form and moisture content in dogs fed once daily.
\end{abstract}

Key words: Dogs: Faeces: Texturized vegetable protein: Soya: Beef

Faecal moisture content can determine whether faeces appear soft or firm, and faecal character can influence whether owners are satisfied with a dog food. Many studies have evaluated the effect of indigestible carbohydrate on moisture content, and some have reported the effect on faecal form $^{(1)}$. Volatile fatty acids produced by fermentation of undigested soluble carbohydrate in the colon of dogs promote water absorption, but excessive fermentation can result in osmotic diarrhoea when the absorptive capacity of the colon is exceeded ${ }^{(1)}$. Thus, soft faeces and increased moisture content are two of the criteria by which the National Research Council $^{(1)}$ has established safe upper limits for the inclusion of carbohydrates in pet foods. Poorly fermented insoluble indigestible carbohydrates, such as cellulose and wheat bran, are viscous and bind water helping to keep faeces well formed, despite increasing faecal wet weight and moisture content $^{(1)}$. Feeding poorly digested protein can cause liquid faeces $^{(2)}$, and higher moisture content and poorer faecal consistency have been observed in large-breed dogs ${ }^{(3)}$. Nevertheless, none of these studies has assessed the effect of time of defecation on faecal moisture content or faecal form.

Texturised vegetable protein from soya (TVP) is commonly included in commercial dog foods, because it retains the appearance of meat during canning. This TVP is an economical source of protein but also contains carbohydrate (oligosaccharides and polysaccharides), only some of which (sucrose and starch) are digestible. The polysaccharides are mostly composed of a pectin-like acidic polysaccharide and

\footnotetext{
Abbreviation: TVP, texturised vegetable protein from soya.

*Corresponding author: R. C. Hill, fax +352 392 6125, email hillr@ufl.edu

† Present address: 17028 E Wildcat Trail, Rio Verde, AZ 85263, USA

‡ Present address: 11860 Spectrum Center, Reston 1650, VA 20190, USA.
}

$\S$ Present address: Department of Small Animal Medicine and Surgery, College of Veterinary Medicine, Texas A\&M University, College Station, TX 77843 USA. 
an arabinogalactan, both of which are indigestible and easily fermentable $^{(4)}$. Previously, we have shown in dogs that the pre-caecal digestibility of protein from TVP is only slightly less than that of beef protein, but that the pre-caecal digestibility of $\mathrm{N}$-free extract, representing carbohydrate, is much reduced in high-TVP diets ${ }^{(5)}$. During this previous study, it was observed that the faeces produced appeared to be softer in the afternoon than in the morning. Thus, the purpose of the present study was to determine whether faecal moisture content differed from morning to afternoon in dogs consuming increasing amounts of TVP.

\section{Experimental methods}

The present study was approved by the University of Florida Institutional Animal Care and Use Committee, and dogs were cared for according to the standard recommendations ${ }^{(6)}$. Each of four canned diets was fed in a Latin Square design for ᄃ 1 week per diet to eight healthy intact male hound dogs in four groups, with two dogs randomly assigned to each group. The composition of the diets and the conditions under which the dogs were maintained have been described previously $^{(5)}$. All four diets contained approximately $77 \%$ moisture and, on a DM basis, $24 \mathrm{MJ} / \mathrm{kg}$ gross energy, $23 \%$ crude protein, $32 \%$ crude fat, $31 \% \mathrm{~N}$-free extract and $1 \%$ crude fibre. The proportion of dietary protein from TVP:beef was 0:100, 14:86, 29:71 and 57:43, respectively, and soya carbohydrate partially replaced maize starch as dietary TVP increased.

Dogs were fed a single meal in the morning between 08.00 and 09.00 hours in an amount that maintained body weight, and the amount fed was the same by weight for each diet. The amount to feed was determined during a 2-week acclimatisation period during which dogs were fed the diet with a TVP:beef protein ratio of 14:86. Dogs walked twice daily, and faeces were collected by direct catch into a plastic collection bag in the morning (08.00-10.00 hours) and afternoon (15.00-18.00 hours) of the 6th day of each diet treatment period. The faeces were weighed and then mixed in the collection bag using a spatula. Percentage DM was determined by drying duplicate faecal samples to stable weight in an oven at $105^{\circ} \mathrm{C}$ for $24 \mathrm{~h}$.

Results are reported as means and standard deviations. Data were log-transformed before analysis because variances differed from morning to afternoon. Faecal moisture content, wet and dry weights were compared using a repeated-measures general linear model procedure (SAS system for windows 9.0; SAS Institute, Inc., Cary, NC, USA) ${ }^{(7)}$. Time of collection, percentage of protein from TVP and the interaction between time and the amount of TVP were effects in the model. A type I error of 0.05 was considered significant. The power of the study was $90 \%$ with eight dogs to detect a difference in DM of $4 \%$. The effect of percentage of protein from TVP was also assessed for both morning and afternoon collections separately. Values at each time point were compared using paired $t$ tests with Bonferroni's correction. The effect of TVP on total daily faecal moisture content was assessed similarly.

\section{Results}

Dogs weighed 24 (SD 4) kg at the start and end of the study. Body weight and the amount of food consumed were not different among diets. Of the eight dogs, six defecated both in the morning and afternoon when fed all the diets, one did not defecate in the morning when fed the diet containing 14\% protein from TVP and one did not defecate in the afternoon except when fed the diet containing $57 \%$ protein from TVP.

There was an interaction between time of defecation and percentage of TVP in the diet (Fig. 1; $P=0 \cdot 003$ ). Faecal moisture content was greater in the afternoon than in the morning (79 (SD 7) $v .71$ (SD 4) \%; $P=0.01$ ) and increased with increasing TVP in the diet from 70 (SD 4) \% when there was no TVP in the diet to 80 (SD 6) \% when $57 \%$ protein was from TVP $(P \leq 0 \cdot 0001)$. Faecal moisture content increased as TVP increased in the diet both in the morning $(P=0.0007)$ and in the afternoon $(P \leq 0 \cdot 0001)$. Moisture content differed from morning to afternoon with TVP in the diet, but there was no difference when there was no TVP in the diet (Table 1).

There was no evidence of a difference from morning to afternoon in either faecal wet weight (99 (SD 35) v. 128 (SD 66) g, respectively) or faecal dry weight (28 (SD 8) v. 24 (SD 9) g, respectively), and there was no interaction with the amount of dietary TVP. Total daily faecal wet weight doubled as TVP increased in the diet $(P \leq 0.0001)$ from 149 (SD 46) $\mathrm{g}$ when there was no TVP in the diet to 301 (SD 88) g when there was $57 \%$ protein from TVP in the diet. Daily faecal moisture content for the morning and afternoon samples combined increased $(P \leq 0 \cdot 0001)$ from 70 (SD 3) to 80 (SD 3) $\%$ with increasing TVP in the diet.

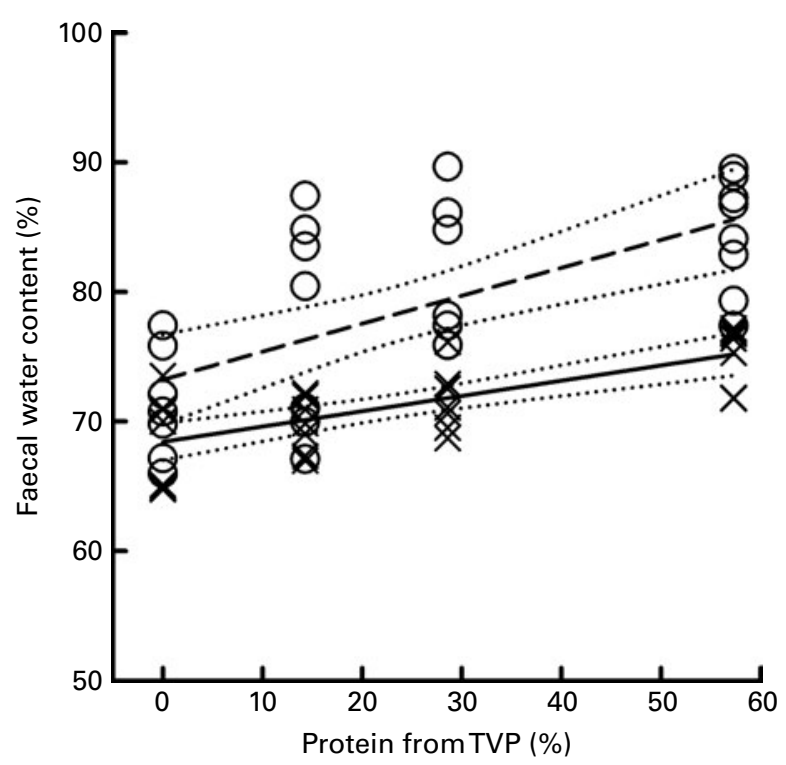

Fig. 1. Moisture content of faeces produced in the morning $(x)$ and afternoon $(O)$ by eight dogs as texturised vegetable protein from soya (TVP) increased in the diet. The solid and dashed lines represent the regression lines for morning and afternoon faeces, respectively. Dotted lines represent the $95 \%$ confidence limits. There was an interaction between time of defecation and percentage of protein from TVP in the diet $(P=0.003 ; n 7-8)$. 
Table 1. Moisture content of faeces collected in the morning and afternoon in eight dogs fed four diets containing increasing amounts of texturised vegetable protein from soya

(Mean values with their standard errors)

\begin{tabular}{|c|c|c|c|c|c|c|}
\hline \multicolumn{2}{|c|}{ Source of dietary protein (\%) } & \multicolumn{3}{|c|}{ Moisture content $(\%)^{\star}$} & \multicolumn{2}{|c|}{$n$} \\
\hline TVP & Beef & Morning & Afternoon & Pooled SE & Morning & Afternoon \\
\hline 0 & 100 & $69^{a, c}$ & $71^{a, c}$ & 1 & 8 & 7 \\
\hline 14 & 86 & $70^{\mathrm{a}, \mathrm{c}}$ & $78^{\mathrm{b}, \mathrm{d}}$ & 2 & 7 & 7 \\
\hline 29 & 71 & $72^{\mathrm{a}, \mathrm{c}, \mathrm{d}}$ & $81^{\mathrm{b}, \mathrm{d}, \mathrm{e}}$ & 2 & 8 & 7 \\
\hline 57 & 43 & $75^{\mathrm{a}, \mathrm{d}}$ & $84^{\mathrm{b}, \mathrm{e}}$ & 2 & 8 & 8 \\
\hline
\end{tabular}

TVP, texturised vegetable protein from soya.

$\mathrm{a}, \mathrm{b}$ Mean values within a row with unlike superscript letters were significantly different from morning to afternoon $(P \leq 0.05)$.

${ }^{\mathrm{c}, \mathrm{d}, \mathrm{e}}$ Mean values within a column with unlike superscript letters were significantly different between the diets $(P \leq 0.05)$.

* Mean values were significantly different from morning to afternoon $(P=0.01)$ and among diets $(P \leq 0.0001)$, and there was an interaction between time and diet $(P=0.003)$.

\section{Discussion}

Faecal moisture content was greater in the afternoon than in the morning when TVP was included in the diet, and the difference increased with the amount of TVP. Soya carbohydrate was probably responsible for this change. We have previously shown, using the same batch of food and similar dogs, that soya protein was only slightly less digestible in the small intestine than beef protein, but that increasing amounts of $\mathrm{N}$-free extract were not digested in the small intestine $(20,26,29$ and $38 \%)$ as TVP increased in these diets ${ }^{(5)}$. This change in N-free extract digestibility follows the decrease in digestible maize starch and the increase in indigestible soya carbohydrate as TVP increased in the diets.

The increase in faecal water content in the afternoon suggests that there was a relative reduction in water absorption, perhaps because there was insufficient time for the colon to absorb water and volatile fatty acids. The canine colon is short compared with that of herbivores, which limits the capacity of the colon to ferment undigested carbohydrate and absorb volatile fatty acids. Addition of fibre tends to shorten oro-anal transit time ${ }^{(8)}$. The residence time in the colon may have been insufficient to allow absorption of the increased amounts of volatile fatty acids generated by fermentation of unabsorbed soya carbohydrate. Previously, we have shown that, on average, ingested food from these diets reaches the ileocolic junction of dogs of this breed and size within $1 \mathrm{~h}$ of the morning feed; $50 \%$ of the ingesta reaching the ileocolic junction within $7 \mathrm{~h}$ and $95 \%$ within $12 \mathrm{~h}$ of the morning feed $^{(8)}$. As the afternoon defecation occurred only $7-10 \mathrm{~h}$ after feeding, the colonic residence time for the ingesta that emerged as afternoon faeces must have been relatively short $(0-6 \mathrm{~h})$, whereas ingesta would have resided in the colon for much longer before emerging as morning faeces (12-17h), assuming almost complete evacuation at each defecation.

The average faecal water content in the present study was much higher than expected based on the results of a previous study, in which dogs of this size and breed were fed these diets. In the earlier study, as in the present study, faecal water content increased and faecal consistency was subjectively observed to change from very firm to soft or liquid as TVP increased in the diet ${ }^{(5)}$. However, faecal water content was $10 \%$ lower in that earlier study, only increasing from 61 to $72 \%$ as TVP replaced beef in the diet. Many of the dogs in the earlier study defecated only once daily in the morning unless they were being fed a high-soya diet, whereas, in the present study, almost all the dogs defecated twice daily even when fed diets containing little or no TVP. As the morning defecation tends to be drier, this may partly explain the lower moisture content in the earlier study. The duration of each diet period was also longer (3 weeks) in the earlier study compared with 1 week in the present study. Thus, the colon, its mucosa and bacterial population had more time to adjust to each new diet in the earlier study. The caecal pool, concentration and absorption of volatile fatty acids increased progressively over $21 \mathrm{~d}$ in rats when soya fibre was added to a fibre-free $\operatorname{diet}^{(9)}$. Colonic mucosal architecture, energetics and absorption have also been shown to be affected by the amount of protein and fibre in the diet of $\operatorname{dogs}{ }^{(10,11)}$. Therefore, it is possible that given more than 1 week to adapt, the size of the colon could have increased and allowed longer retention of faeces. This would allow dogs not to defecate so often, allow more time for water and volatile fatty acid absorption and might reduce the effect of TVP on the quality of faeces in the afternoon. These dogs were also of moderate size. Faecal moisture, faecal softness, large-intestinal transit time and permeability and faecal concentrations of $\mathrm{Na}, \mathrm{K}$, lactic and volatile fatty acids are higher in large-breed dogs ${ }^{(12-14)}$, so results might be different for a different size of dog.

In summary, time of defecation influences the water content and may affect faecal form and the owner's perception of a diet when dogs are fed once daily a diet containing TVP from soya. This may limit the amount of TVP containing indigestible soya carbohydrate that may be included in dog food. Nevertheless, little is known about the relationship of dietary ingredients, colonic function and faecal form or the time that the colon takes to adapt to a new diet. It is possible that more soya carbohydrate may be included without causing alarm to a dog's owner if the adaptation time is longer or the amount of other nutrients in the diet such as insoluble fibre, $\mathrm{Mg}$ or $\mathrm{Ca}$, that may affect faecal water content and form, is changed. 


\section{Acknowledgements}

R. C. H., C. F. B., J. E. B. and M. D. F. have been partly supported by donations from or employed by various pet food companies. Funding was provided by Archer Daniels Midland, Alpo Pet Foods, Inc. and the Alpo Research Fellowship. Data contributed to a PhD thesis at the University of Florida but otherwise have not been published previously. The contributions of authors were as follows: R. C. H. is the primary author. C. F. B. is the primary investigator. G. W. E., M. D. F., J. L. H. and J. E. B. helped in designing the diets, and performed the study and interpreted the results. Each author read and approved the contents of the manuscript. The present study would not have been possible without the technical assistance of R. C. Littell of the Department of Statistics.

\section{References}

1. Subcommittee on Dog and Cat Nutrition, Committee on Animal Nutrition \& National Research Council (2006) Nutrient Requirements of Dogs and Cats. Washington, DC: National Academy Press.

2. Taylor RJF, Worden AN \& Waterhouse CE (1958) The diet of sledge dogs. Br J Nutr 13, 1-16.

3. Hernot DC, Biourge VC, Martin LJ, et al. (2005) Relationship between total transit time and faecal quality in adult dogs differing in body size. J Anim Physiol Anim Nutr (Berl) 89, 189-193.

4. Aspinall GO, Begbie R \& McKay JE (1967) Polysaccharide components of soybeans. Cereal Sci Today 12, 224-261.
5. Hill RC, Burrows CF, Ellison GW, et al. (2001) The effect of texturized vegetable protein from soy on nutrient digestibility compared to beef in cannulated dogs. J Anim Sci 79, 2162-2171.

6. National Research Council (1985) Guide for the Care and Use of Laboratory Animals, Publication No. 85-23 (rev.). Bethesda, MD: National Institutes of Health.

7. Littell RC, Milliken GA, Stroup WW, et al. (1996) SAS System for Mixed Models. Cary, NC: SAS Institute, Inc.

8. Hill RC, Burrows CF, Ellison GW, et al. (2000) The effect of texturized vegetable protein containing soy carbohydrate on oroileal transit of chromic oxide in cannulated dogs. J Anim Sci 78, 2633-2638.

9. Levrat MA, Behr SR, Remesy C, et al. (1991) Effects of soybean fiber on cecal digestion in rats previously adapted to a fiber-free diet. J Nutr 121, 672-678.

10. Hallman JE, Wallace EA \& Clemens ET (1993) Protein source and their effects upon canine colonic morphology and mucosal energetics. Nutr Res 13, 1273-1281.

11. Hallman JE, Reinhart GA, Wallace EA, et al. (1996) Colonic mucosal tissue energetics and electrolyte transport in dogs fed cellulose, beet pulp or pectin/gum arabic as their primary fiber source. Nutr Res 16, 303-313.

12. Hernot DC, Weber MP, Biourge VC, et al. (2004) Relationship between electrolyte apparent absorption and fecal quality in adult dogs differing in body size. J Nutr 134, 2031S-2034S

13. Hernot DC, Dumon HJ, Biourge VC, et al. (2006) Evaluation of association between body size and large intestinal transit time in healthy dogs. Am J Vet Res 67, 342-347.

14. Hernot DC, Nery J, Biourge VC, et al. (2008) Colonic permeability is higher in Great Danes compared with smaller breed-dogs. J Anim Physiol Anim Nutr (Berl) 93, 703-709. 